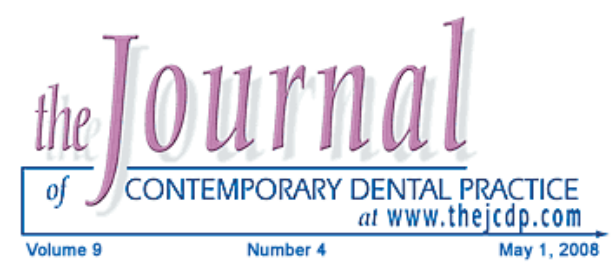

\title{
Clinical and Radiological Findings Related to Tuberous Sclerosis Complex: A Case Report
}

\section{Siddharth Gupta, BDS; Rahul Bhowate, MDS; Shirish S. Degwekar, MDS}

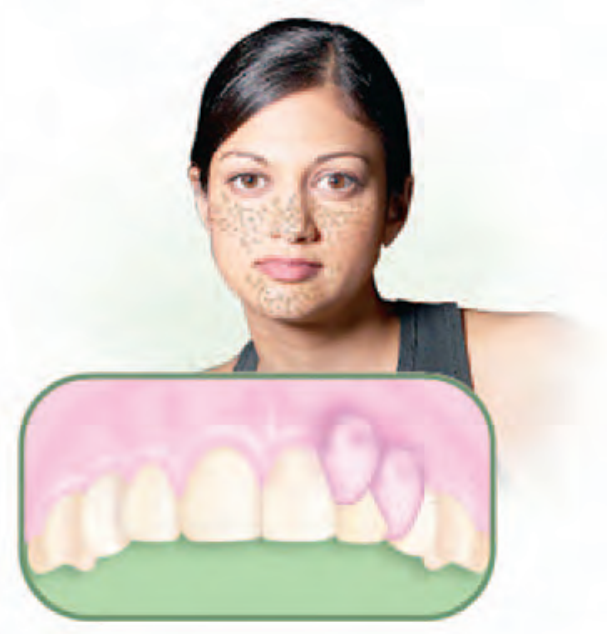

Abstract

Aim: The aim of this report is to present the intraoral and extraoral clinical features of a young female patient with tuberous sclerosis complex (TSC) who exhibited multiple hamartomas of various organ systems including a fibromatous growth on the gingiva.

Background: TSC is a rare neurocutaneous syndrome exhibiting multiple hamartomatous proliferations that may involve multiple organs such as the brain, kidney, heart, eyes, lungs and skin. Oral manifestations such as enamel pitting and fibromatous growth of the gingiva are commonly seen in patients with TSC.

Report: A 16-year-old female patient presented with a painless interdental gingival growth in the maxillary left incisor and canine region that bled occasionally. Associated findings were adenoma sebaceum (angiofibromas) on the face, a Shagreen patch on the lumbosacral region, ash leaf spots on the trunk, and subangual fibromas (Koenen's tumor) on the nails of fingers and toes. The final diagnosis of TSC was made on the basis of the clinical findings of the skin, computerized tomography (CT) findings of the brain and kidney, ultrasonographic findings of kidney, and a histopathologic evaluation of the gingival growth which met the major and minor criteria required for a diagnosis of TSC.

Summary: This case report is a good example of the complex nature of patients with TSC. The diagnosis and management of these patients varies depending on the specific presentation of the disease. Dentists need

(C) Seer Publishing 
to be mindful of the systemic issues as well as oral conditions related to this disease. Dental practitioners are advised to work closely with the patient's physician during treatment.

Keywords: Tuberous sclerosis complex. TSC, hamartomas, angiofibromas, shagreen patch, subangual fibromas

Citation: Gupta S, Bhowate R, Degwekar SS. Clinical and Radiological Findings Related to Tuberous Sclerosis Complex: A Case Report. J Contemp Dent Pract 2008 May; (9)4:085-091.

\section{Introduction}

Tuberous sclerosis is rare syndrome with an estimated incidence of 1 in 6,000 to 1 in 10,000 live births, with no ethnic clustering. ${ }^{1-6}$ The name tuberous sclerosis is derived from the characteristic tuber or root-like growth occurring in the brain which calcifies with age and becomes sclerotic. The disorder was once known as epiloia or Bourneville's disease and was first identified by a French physician Bourneville in 1880. ${ }^{4,7}$

There is family history of the disease in $50 \%$ of affected patients, with a autosomal mode of inheritance and variable expressivity. ${ }^{4,5}$ Some individuals acquire tuberous sclerosis complex (TSC) through a process called gonadal mosaicism. These patients have parents with no apparent defects in the two genes that cause the disorder. Yet these parents can have a child with TSC because a portion of one of the parent's reproductive cells (sperm or eggs) can contain the genetic mutation without the other cells of the body being involved. In cases of gonadal mosaicism genetic testing of a blood sample might not reveal the potential for passing the disease to offspring. ${ }^{4}$ TSC is caused by defects, or mutations, on two genes-TSC1 and TSC2. ${ }^{1,2,4}$ Only one of the genes needs to be affected for TSC to be present. The TSC1 gene, discovered in 1997, is on chromosome 9 (9q34) and produces a protein called hamartin. The TSC2 gene, discovered in 1993, is on chromosome 16 (16p13.3) and produces the protein tuberin. ${ }^{2,46}$ These proteins act as tumor growth suppressors to regulate cell proliferation and the differentiation of nerve cell division to form new generations of cells which acquire individual characteristics. ${ }^{4}$

This report of TSC presents the intraoral and extraoral clinical features of a 16-year-old female patient having multiple hamartomas of various organ systems including a fibromatous growth on the gingiva.

\section{Case Report}

A 16-year-old female patient reported to the Department of Oral Medicine \& Radiology, Sharad Pawar Dental College and Hospital, Wardha, India with the complaint of a localized gingival growth in the maxillary left incisor and canine region that bled occasionally during the past four years.

The patient had multiple brown lesions over her face that gradually spread over the neck and part of her hands. There was no history of bleeding, itching, pain, or change in the size of the lesions since she was six years of age. However, she noticed an increase in the number of lesions during the past two years. None of her family members suffer from any systemic disease or similar condition.

A clinical examination revealed multiple angiofibromas appearing as well defined roughly round to oval dark brown firm papules all over her face, neck, and forearms (Figure 1). A Shagreen

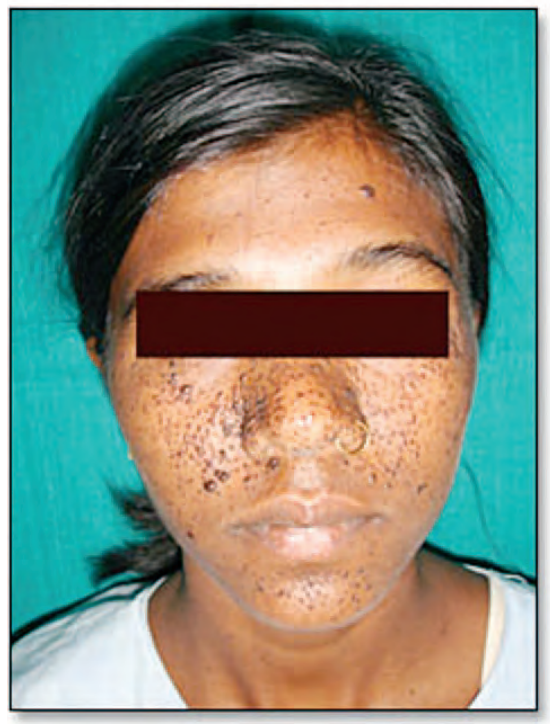

Figure 1. Angiofibromas appearing as dark brown firm papules all over her face. 


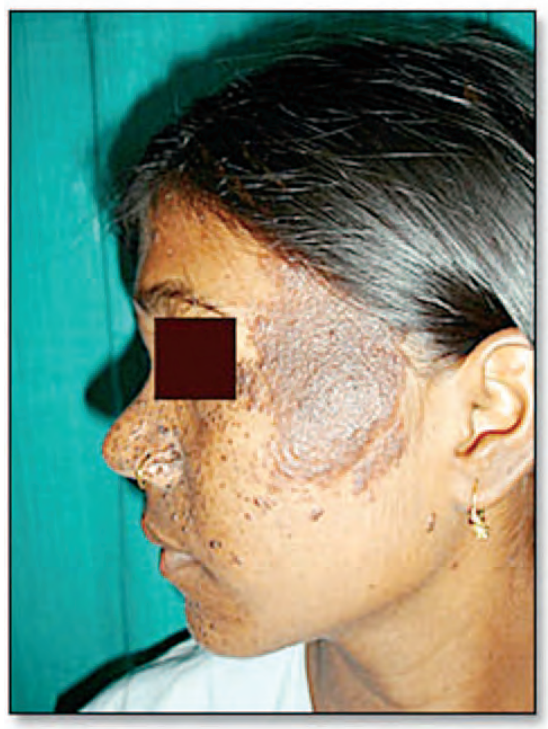

Figure 2. A Shagreen patch or hyperpigmented plaque.

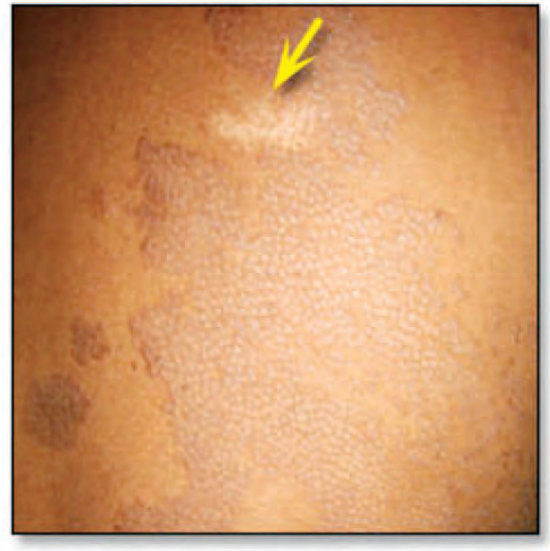

Figure 3. A Shagreen patch and an Ash-leaf spot appearing as hyperpigmented plaque in the lumbosacral region with a few leaf like hypopigmented patches (arrow), respectively.

patch (hyperpigmented plaque) was present over the left side of the face (Figure 2). Multiple Shagreen patches were also present on the thorax, abdomen, and back, especially in the lumbosacral region, along with a few leaf-like hypopigmented patches (Ash-leaf spots) (Figure 3).

Fibrous growths were present at nail folds of the hands and feet (Periungual Fibromas or Koenen's Tumors) (Figure 4).

A localized interdental gingival growth was found in the maxillary left incisor and cuspid region. The

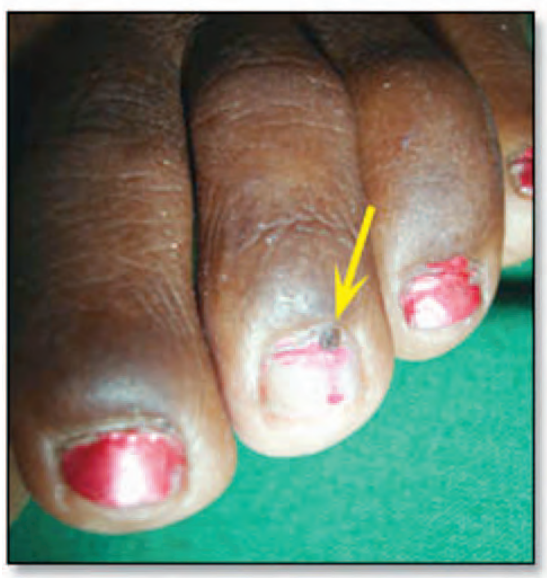

Figure 4. Koenen's Tumors: Fibrous growths at the nail fold of the feet.

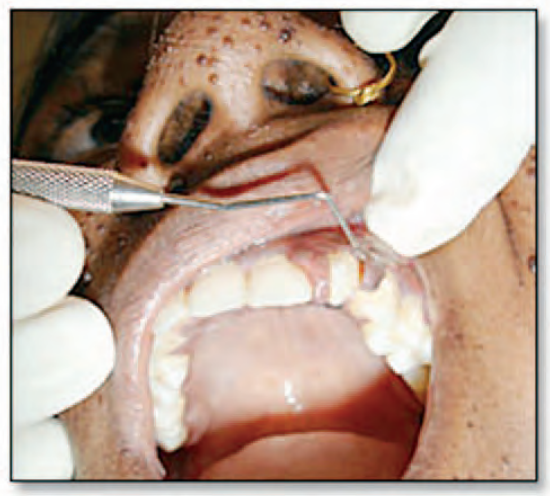

Figure 5. Localized interdental gingival growth.

lesion involved the marginal gingiva and was fibrotic but freely movable and associated with slight bleeding (Figure 5).

A periapical radiograph of the maxillary left incisor and canine region showed a rotated maxillary left lateral incisor. In addition a panoramic radiograph showed a rotated mandibular left canine along with generalized pulpal calcification of the posterior teeth (Figure 6).

A lateral skull radiograph revealed the presence of intracranial calcification. A CT brain scan revealed multiple tubers (cortical tubers) of various densities in both hemispheres (Figure 7). A CT kidney scan revealed hypodense areas of fat (angiomyolipomas) in the kidneys (Figure 8).

An excisional biopsy of the fibrous growth was performed. A hematoxylin and eosin stained histopathologic section of the lesion revealed 


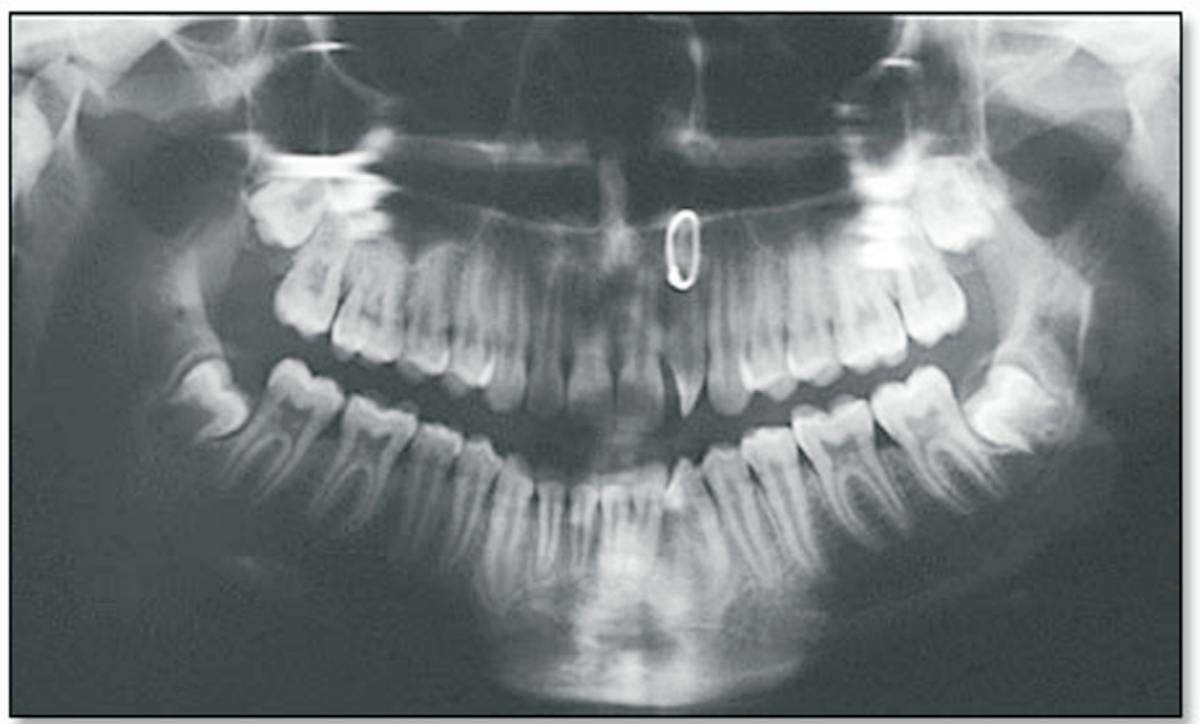

Figure 6. Panoramic radiograph showing a generalized pulpal calcification of posterior teeth and rotated mandibular left canine and maxillary left lateral incisor teeth.

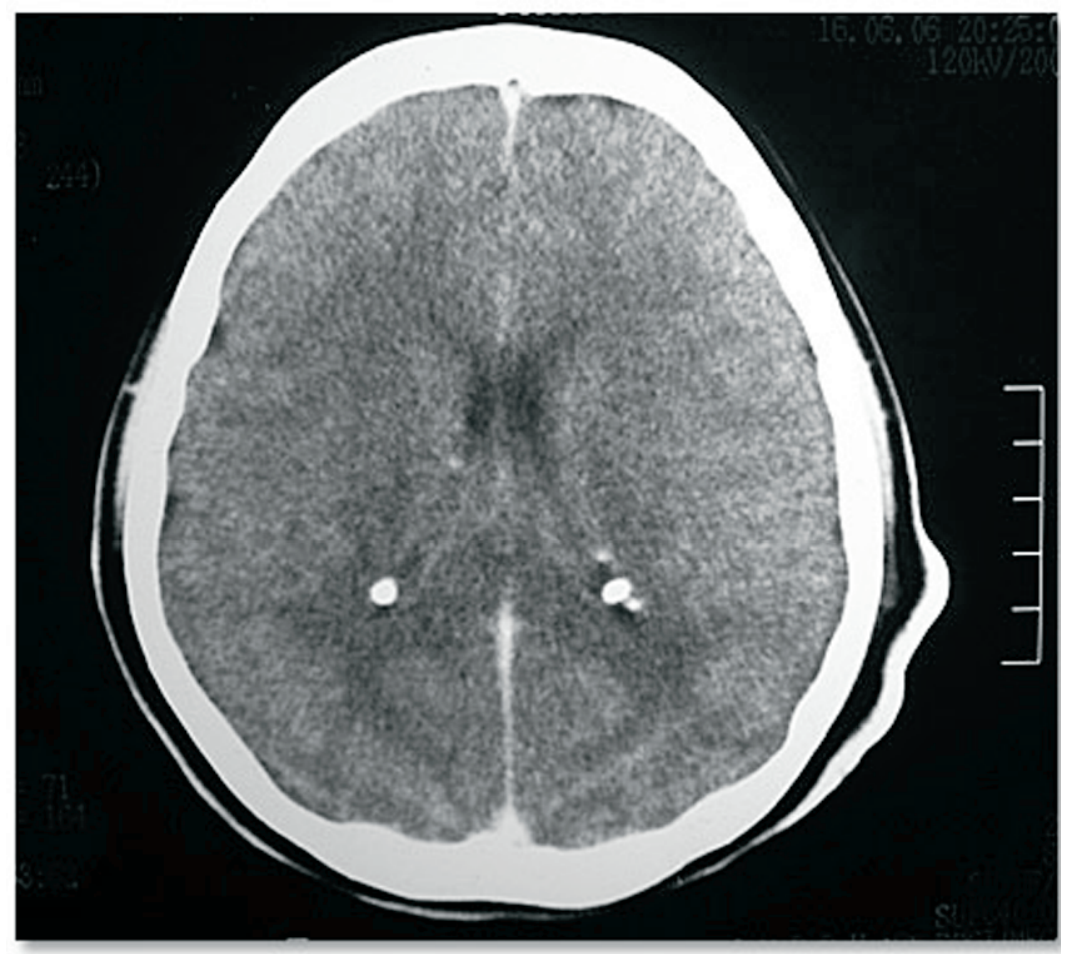

Figure 7. CT brain scan showing multiple tubers (cortical tubers) of various densities in both hemispheres. 


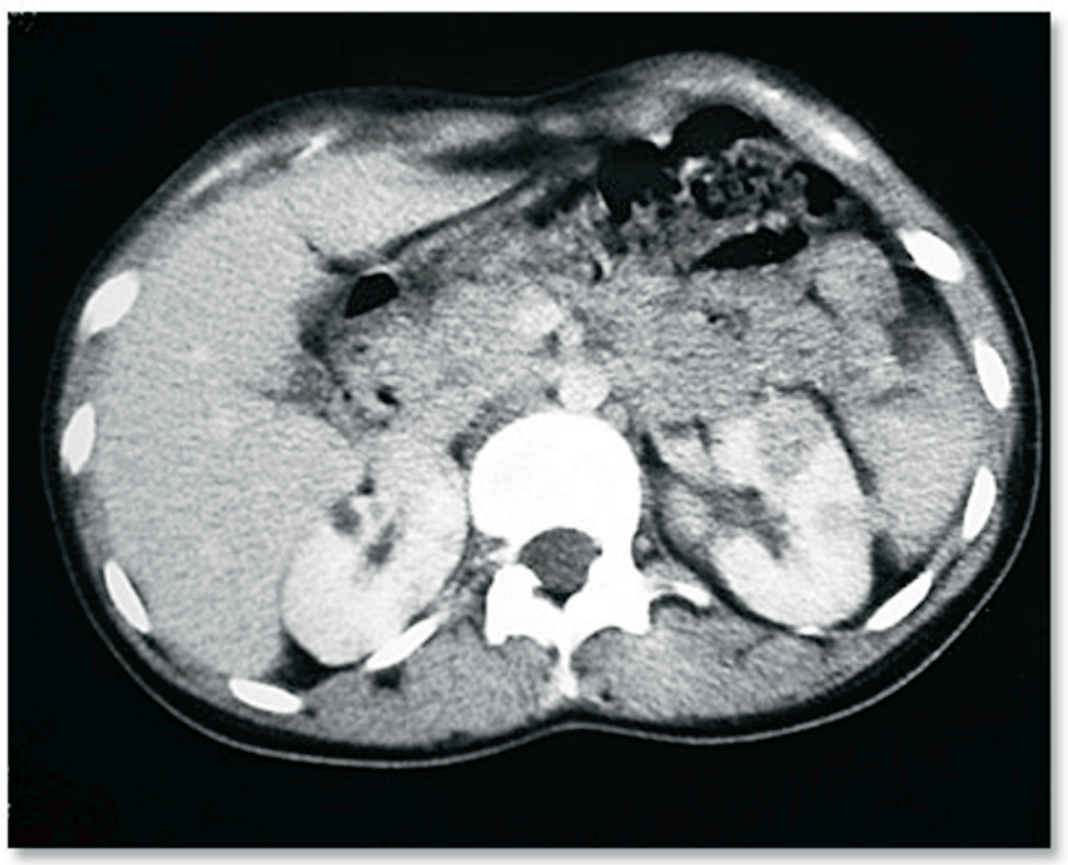

Figure 8. CT kidney scan showing hypodense areas of fat (angiomyolipomas) in both kidneys.

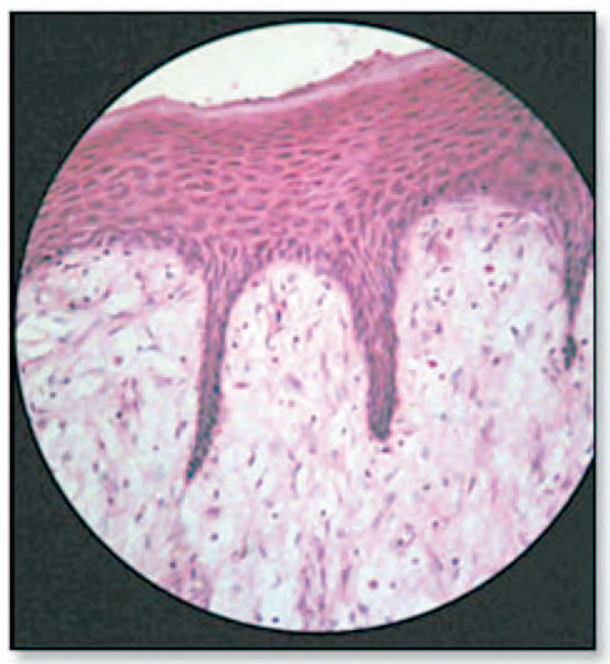

Figure 9. Hematoxylin and Eosin stained histopathologic section showing presence of collagen fibers and elongated rete-pegs into connective tissue (fibrous growth).

a hyperparakeratinized proliferative stratified squamous epithelium with mild chronic inflammatory cells, collagen fibers, and elongated rete-pegs in the connective tissue (Figure 9).

\section{Discussion}

The diagnosis of TSC has evolved from only clinical observations then progressed to the use of anatomicopathological studies to the present when TSC is being studied using molecular biology. ${ }^{6}$ The disease develops as an abnormal growth of ectodermic and mesodermic cells producing benign tumors extending to areas of the head, heart, brain, and kidneys. The term epiloia (epilepsy, low intelligence, and adenoma sebaceum) was proposed by Campbell and Sherlock. ${ }^{2}$ This designation may be of some use in describing the disease, although all three signs are rarely present. The classic triad of epiloia is seen in only $30 \%$ of affected individuals. ${ }^{2,6}$

The knowledge gained from a thorough diagnostic process is invaluable to the well-being of dental patients with TSC. In this context the anesthetics and sedatives used in dentistry may affect patients with TSC, therefore, these interactions are reviewed here. The dental clinician treating patients with TSC should consider the genetic aspects of the disease as well as possible alterations of the heart, kidneys, skin, eyes, face, bones, lungs, kidneys, and the central nervous system. ${ }^{6}$

In 1998 the National Institutes of Health published a set of diagnostic criteria. The criteria were composed of clinical and radiographic features which were divided into major and minor categories. A patient must present with two of the major criteria or one major and two minor 
Table 1. Diagnostic Criteria: A definitive diagnosis of TSC requires either two of the major criteria or one major and two minor criteria.

\begin{tabular}{|l|l|}
\hline \multicolumn{1}{|c|}{ Major features } & \multicolumn{1}{|c|}{ Minor features } \\
\hline Facial angiofibromas & Multiple pits in dental enamel \\
\hline Ungula and periungual fibroma & Hamartomatous rectal polyps \\
\hline Hypomelanotic macules & Bone cysts \\
\hline Shagreen patch & "Migration tracts" \\
\hline Cortical tuber & Gingival fibromas \\
\hline Subependymal nodule & Nonrenal hamartoma \\
\hline Subependymal giant cell astrocytoma & Retinal achromic patch \\
\hline Multiple retinal nodular hamartomas & "Confetti" skin lesion \\
\hline Cardiac rhabdomyoma & Multiple renal cysts \\
\hline Lymphangiomyomatosis & \\
\hline Renal angiomyolipoma & \\
\hline
\end{tabular}

criteria for a definitive diagnosis of TSC. No single criterion, found either clinically or radiographically, is present in all patients. Diagnostic criteria ${ }^{1,2,3}$ for TSC is given in Table 1.

Angiofibromas or adenoma sebaceum are firm, discrete, red brown, telengiectatic papules, $1-10 \mathrm{~mm}$ in diameter extending from the nasolabial furrows to the cheeks and are occasionally found in the ears. It is seen in about $70 \%$ of patients. ${ }^{2,3,9}$

Periangual and subungual fibromas (Koenen's tumor) are firm, flesh colored growth from nail folds. They are usually $5-10 \mathrm{~mm}$ in length. It is seen in $15-20 \%$ of individuals. $2,3,9$ The Shagreen patch is a localized, irregular, cobbled-stoned, yellowish-brown or skin colored, plaque resembling pigskin that is most often found in the lumbosacral area or the face. It typically gives the overlying skin an "orange peel" appearance. They are actually connective tissue nevi found in $20-50 \%$ of affected individuals. ${ }^{2,3,9}$

Hypopigmented ash leaf spots are dull white macules with an average diameter of $1-3 \mathrm{~cm}$. The lesion vary in number from 1-100. They are seen in about $85 \%$ of patients with TSC in a confetti-like distribution. ${ }^{2,9}$

Mental deficiency is present in $60-70 \%$ of cases. Epilepsy is seen in almost all mentally retarded patients (90\%) and in some $70 \%$ of those with normal intelligence. ${ }^{2,3}$ Ocular signs (achromic patchs) are hypopigmented spots in the iris, seen in about $50 \%$ patients with TSC. ${ }^{2}$

Approximately $50 \%$ of affected individuals exhibit renal hamartomas in the form of angiomyolipomas, a benign tumor of the renal parenchyma and less commonly with polycystic changes. These are often bilateral. ${ }^{2,3,9,10}$ It is rare to find them in the oral cavity, nasal cavity, ear lobe, and salivary glands. ${ }^{8}$

Cardiac rhabdomyomas occur in $30-50 \%$ of affected patients being responsible for early death. ${ }^{2,3}$ Approximately $75 \%$ of severely affected patients die before the age of 25 years secondary to cardiac involvement. ${ }^{11}$ There can be a presence of increased dyspnoea and a recurrent spontaneous pneumothorax. Other features 
are hamartomatous colonic polyps, pituitaryadrenal dysfunction, thyroid disorders, premature puberty, gigantism, and diffuse cutaneous reticulohistiocytosis. $^{2}$

Plain skull radiographs demonstrate calcifications or areas of increased density in about $50 \%$ of patients with TSC.,3 Cortical thickening and scattered radiolucent cyst-like changes are frequently seen in the long and small bone of hands and feet. There may be areas of increased radiodensity in the spine and pelvis. ${ }^{12}$ Fibrolipomatous hamartoma was also noted in TSC patients as a well defined unilocular radiolucency. ${ }^{5}$ The $\mathrm{CT}$ findings are subependymal nodule (SEN), subependymal giant cell astrocytoma (SEGA), parenchymal hamartomas, and ventriculomegaly. The typical CT appearance of TSC consists of calcified periventricular nodules projecting into the lateral ventricles and hypoattenuated parenchymal lesions. Magnetic resonance imaging (MRI) is more sensitive in detecting parechymal lesions. ${ }^{1,2,4}$

Common intraoral findings include multiple discrete areas of fibrous hyperplasia and enamel pitting. ${ }^{3,6,11}$ The fibrous nodules most frequently affect the anterior portions of the gingiva, but it is not rare to find them on the lips, tongue, and palate. They may be normal-colored or red and typically appear in late childhood. Although a prevalence of $11 \%$ has been reported, the true frequency of these findings may be significantly greater. A study of 39 patients by Lygidakis ${ }^{14}$ revealed oral fibromas in $56 \%$ of the subjects. Enamel pits, which are best seen with disclosing solution, randomly occur on all tooth surfaces. ${ }^{3,6}$ Less common oral manifestations include hemangiomas, facial asymmetry, a high-arched palate, bifid uvula, cleft lip/palate, delayed eruption, and diastemas. ${ }^{11}$

Passive protection of the oral tissues is needed to prevent injury during an epileptic crisis and instrumentation should be used with caution. Removable dentures are contraindicated due to the risk of fracture and possible aspiration in the event of convulsions. Esthetic fixed prostheses are a safer alternative. Use of a rubber dam may also be contraindicated due to the potential of aspirating the clamp during a convulsion.

Every patient should be evaluated according to the frequency and control of his or her epileptic attacks. ${ }^{15}$ Erythromycin should not be administered to these patients because blood levels may rise to toxic levels. Bleeding time should be determined before conducting invasive procedures and drugs such as aspirin or ibuprofen should be avoided. ${ }^{15}$ Another complication of dental management in patients with TSC is use of deep sedation or general anesthesia for patient control during treatment procedures due to the mental retardation factor. There may be the presence of pulmonary fibrous degeneration or cysts causing dyspnea and even a spontaneous pneumothorax. Dental treatment should be postponed until the pulmonary situation has been stabilized. ${ }^{16}$ A complete multi-organ exploration before anesthesia is very important due to the risk of cardiac, kidney, and pulmonary problems, as well as frequent epileptic crises. The dentist should always implement effective preventive measures to achieve a good post-treatment prognosis.

Recent studies promote the combination of anesthetic agents such as thiopentone, vecuronium, and nitrous oxide with isoflurane when using general anesthesia on dental patients. ${ }^{17}$

\section{Summary}

This case report is a good example of the complex nature of patients with TSC. The diagnosis and management of these patients varies depending on the specific presentation of the disease. Dentists need to be mindful of the systemic issues as well as oral conditions related to this disease. Dental practitioners are advised to work closely with the patient's physician during treatment. 


\section{References}

1. McCall T, Steven S, Salzman KL, Fults DW. Tuberous Sclerosis: a syndrome of incomplete tumor suppression. Neurosurg Focus 2006; 20(1):E3.

2. Harper JJ, Trembath RC. Genetics and Genodermatosis in: Breathnach, Neil Cox, Christopher Griffiths. Rook's Textbook of Dermatology, 7th edition, Volume - 1 Blackwell, Australia; 2004: pp 12.33-12.37.

3. Damm DD, Tomich CE, White DK, Drummond JF. Intraosseous fibrous lesions of the jaws. Oral Surg Oral Med Oral Pathol Radiol Endol 1999; 87:334-40.

4. Tuberous Sclerosis Fact Sheet National Institute of Neurological Disorders and Stroke (NINDS).mht, NIH Publication No. 02-1846.

5. Celenk P, Alkan A, Canger EM, Günhan O. Fibrolipomatous hamartoma in a patient with tuberous sclerosis: Report of a case. Oral Surg Oral Med Oral Pathol Radiol Endol 2005; 99:202-6.

6. Cutado A, Antonio J, Lopez J. Oral health management implecations in patients with tuberous sclerosis. Oral Surg Oral Med Oral Pathol Radiol Endol 2000; 90:430-5.

7. Mlynarczyk G. Enamel pitting: A common symptom of tuberous sclerosis. Oral Surg Oral Med Oral Pathol Radiol Endol 1991; 71:63-7.

8. Foschini MP, Corti B, DaCol M, Cenzi M, Zanella F, Barbazza R. Angiomyolipoma of the parotid gland a case report. Oral Surg Oral Med Oral Pathol Radiol Endol 1999; 87:738-41.

9. Pai GS, Kamath NK, Vimal, Genodermatoses VAM, Walia RG. IADVL Textbook and Atlas of Dermatology, 2nd edition, Volume - 1, Bhalani Publishing House Mumbai, India; 2003: pp 103-106.

10. Gorlin RJ, Cohen MM, Levin LS. Syndromes of the head and neck. 3rd ed. New York: Oxford University Press; 1990. pp 410-5.

11. Scully C. Orofacial manifestations in tuberous sclerosis. Oral Surg Oral Med Oral Pathol Radiol Endol 1977; 44:706-16.

12. Noer HR, Harmon SD. Skeletal changes in tuberous sclerosis. Medical Annals of the District of Columbia 1966; 35:324-5,350.

13. Dickerson WW. Nature of certain osseous lesions in tuberous sclerosis. Archives of Neurology and Psychiatry 1955; 73:525-9.

14. Lygidakis NA, Linderrbaum RH. Oral fibromatasis in tuberous sclerosis. Oral Surg Oral Med Oral Pathol Radiol Endol 1989; 68:725-8.

15. Sanders BJ, Weddell JA, Dogge N. Managing patients who have seizure. Disorders: dental and medical issues. J Am Dent Assoc 1995; 126:1641-7.

16. Bowen J, Beasley SW. Rare pulmonary manifestations of tuberous sclerosis in children. Pediatr Pulmonol 1997; 23:114-6.

17. Nott MR, Halfacre J. Anesthesia for dental conservation in a patient with tuberous sclerosis. Eur $\mathrm{J}$ Anesthesiol 1996; 13:413-5. 
About the Authors
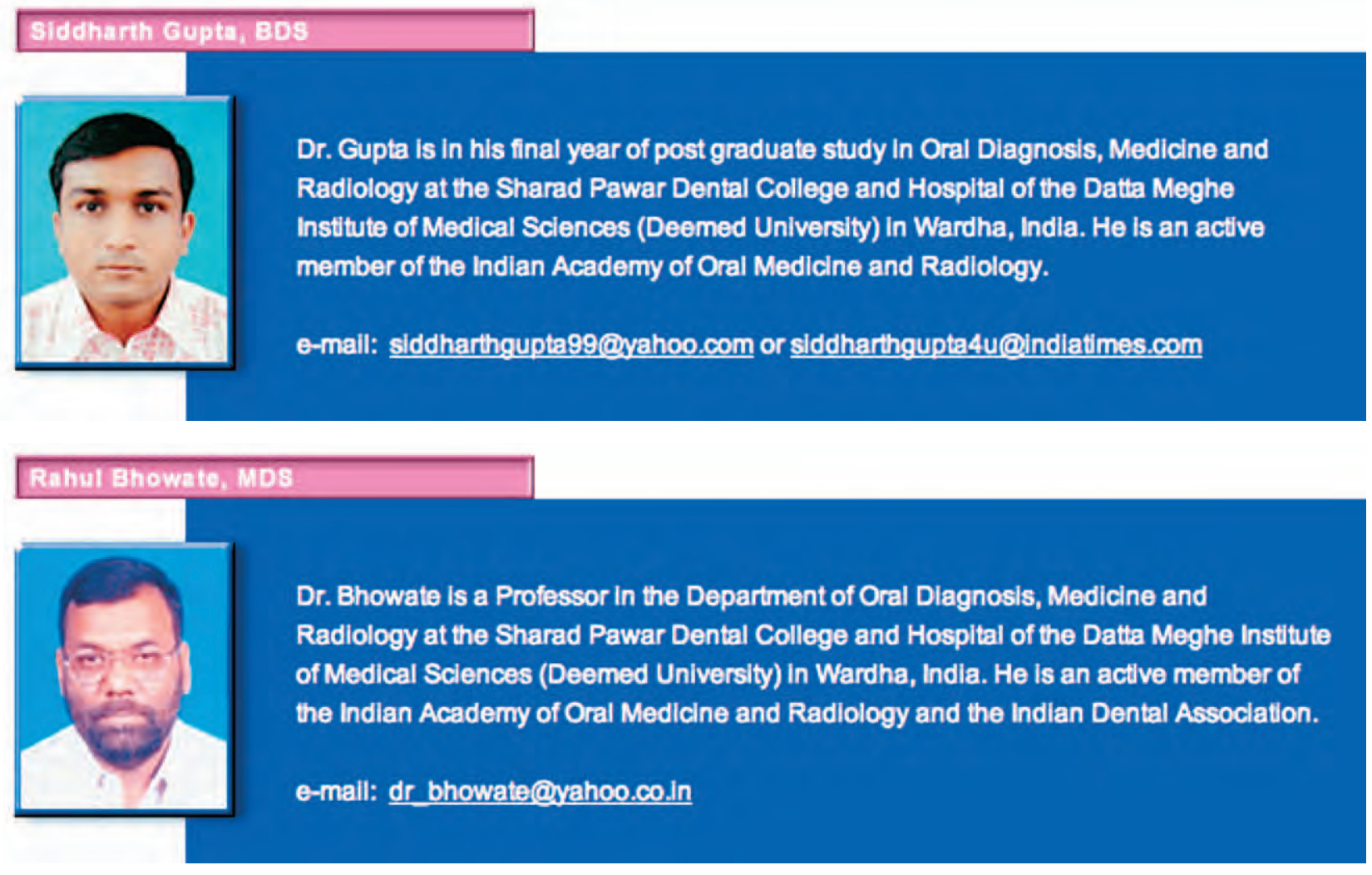

\section{Shlrish 5. Degwokar, MDS}

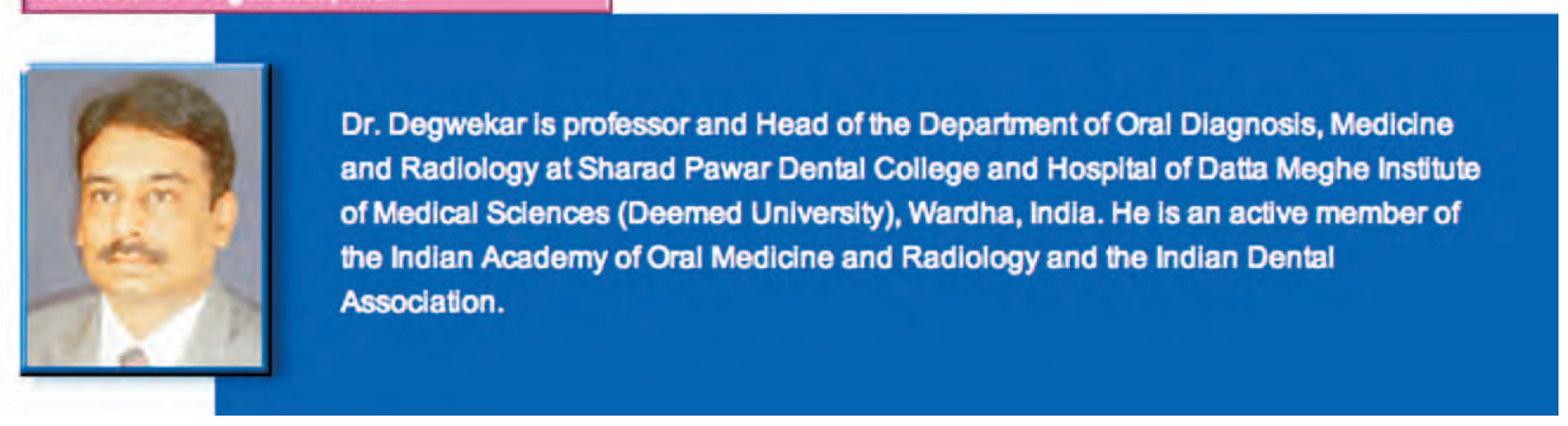

